\title{
Overexpression of Cyclin E and its Low Molecular Weight Isoforms Cooperate with Loss of p53 in Promoting Oncogenic Properties of MCF-7 Breast Cancer Cells
}

\author{
Hamed Montazeri ${ }^{1}$, Saeid Bouzari ${ }^{1}$, Kayhan Azadmanesh $^{2}$, Seyed Nasser Ostad ${ }^{3}$, \\ Mohammad Hossein Ghahremani ${ }^{3 *}$
}

\begin{abstract}
Cyclin E, a key coordinator of the G1 to $S$ transition in the cell cycle, may be deregulated in several malignancies, including breast cancer. The most significant aberration in cyclin $\mathrm{E}$ is its elastase mediated proteolytic cleavage into tumor specific low molecular weight isoforms (LMW-Es). LMW-Es are biochemically hyperactive and biologically drive tumorigenesis in transgenic mouse models. Additionally, expression of LMW-Es has been correlated with poor survival in breast cancer cases. Here we determine whether expression of LMW-Es in a breast cancer cell line that is naturally devoid of these deregulated forms would alter their progression through each phase of the cell cycle. The results revealed that LMW-Es expression resulted in an increased doubling time, concomitant with a predominant increase in the population in the $S$ phase of the cell cycle. Moreover, downregulation of $\mathrm{p53}$ in LMW-Es cells resulted in additional shortening of the doubling time and enrichment of cells in the $S$ and G2/M phases of the cell cycle. Furthermore, expression of LMW-Es sensitized cells to $\beta$-estradiol (E2) mediated growth and changed expression patterns of estrogen receptor and Bcl-2. Intriguingly, expression of LMW-Es could surpass anti-apoptotic effects raised by p53 upregulation. Taken together these studies suggest that overexpression of LMW-Es in collaboration with p53 loss results in altered growth properties of MCF-7 cells, enhancing the oncogenic activity of these ER positive breast cancer cells.
\end{abstract}

Keywords: Cyclin E - breast cancer - low molecular weight isoforms - p53 - estrogen receptor

Asian Pac J Cancer Prev, 16 (17), 7575-7582

\section{Introduction}

Cell cycle progression is governed by cyclins and their kinase partners, the cyclin dependent kinases (CDKs). Modified activity of cyclins can cause aberrant cell proliferation leading to a deregulated cell cycle progression that is often observed in cancer cells (Spruck et al., 1999) .Among the key cell cycle regulators, cyclin $\mathrm{E}$ is of great significance, because of its deregulated expression and prognostic value in many cancers particularly breast cancer (Keyomarsi et al., 1995; Donnellan and Chetty, 1999; Gao et al., 2013; Alsina et al., 2015).

Cyclin E belongs to E-type cyclins (cyclin E1 and E2) which in addition to D-type cyclins (cyclin D1,D2 and D3),constitute the G1 class of cyclins (Koff et al., 1991; Xiong et al., 1991; Lauper et al., 1998). Cyclin E exerts its function by formation of an active complex with CDK2, thereby phosphorylating a series of substrates including retinoblastoma protein ( $\mathrm{Rb}$ )(Weinberg, 1995). $\mathrm{Rb}$ is sequentially phosphorylated by cyclin D/CDK46 complexes followed by cyclin E/CDK2 complex during the early and late G1 phase, respectively. Upon hyperphosphorylation of Rb by cyclin/CDK complexes, $\mathrm{E} 2 \mathrm{~F}$ is released from the $\mathrm{Rb}$ containing complex, allowing it to transactivate many genes whose expressions are required for S phase entry (Ohtani et al., 1995). Other substrates of cyclin E/CDK2 include proteins involved in centrosome duplication (NPM, CP110, Mps1), DNA synthesis (Cdt1), DNA repair (Brca1, Ku70), histone gene transcription(p220/NPAT, CBP/p300, HIRA) and inhibitors of CDKs (CKIs)i.e.p21Waf1/Cip1 and p27Kip1(Hwang and Clurman, 2005). Moreover cyclin E is involved in development and senescence as well (Dulic et al., 1993; Richardson et al., 1995). Knockdown of cyclin E during development does not have a detrimental effect on the developing embryo, however, downregulation of cyclin $\mathrm{E}$ in many types of cancer results in senescence of apoptosis of these cells (Gladden and Diehl, 2003). These results suggest that while the function of cyclin $\mathrm{E}$ is redundant in normal cells or tissues, that many cancer cells become oncogenically addicted to the deregulated expression of cyclin E (Gladden and Diehl, 2003).

Periodic transcription of cyclin E results in its accumulation near G1/S boundary followed by 
autophosphorylation dependent proteolysis in the late S(Ekholm and Reed, 2000). Proper kinetics and expression level of cyclin $\mathrm{E}$ are crucial for its function during G1 to $\mathrm{S}$ phase transition, since its deregulated expression has been correlated with poor patient outcome in various human cancers including breast carcinoma (Keyomarsi and Pardee, 1993; Donnellan and Chetty, 1999; Caldon et al., 2012). In a retrospective studies, cyclin E level has been the best predictor of survival comparing with canonical clinical factors (age, tumor size, nodal status, stage of disease) and biologic markers (steroids and Her-2 receptor status, ploidy, proliferation index, cyclins D1 and D3) (Keyomarsi et al., 2002; Liu et al., 2013). The known mechanisms of these elevated and constitutive expressions include cyclin E gene amplification, overexpression of its mRNA, increased expression of its protein, tumor specific proteolytic cleavage of the full length protein and altered profiles of microRNAs expression(Keyomarsi and Pardee, 1993; Porter et al., 2001; Ekholm-Reed et al., 2004; le Sage et al., 2007; Liu et al., 2009).

The 50-kDa, full length, form of cyclin E, called cyclin EL1, which is encoded from a different spliced variant of the primary cloned cDNA, can be found in both normal and tumor cells (Ohtsubo et al., 1995). However, in addition to the full length cyclin E, a series of low-molecular-weight isoforms (LMW-Es) is uniquely present in some cancers such as breast, colon, ovarian and hematological malignancies (Scuderi et al., 1996; Wang et al., 1996; Harwell et al., 2000; Davidson et al., 2007). Having the mass from 45 to $33 \mathrm{kDa}$, these LMW forms are generated in a tumor-specific post translational cleavage which is distinct from proteasome mediated degradation of cyclinE. Elastase serine protease mediates this processing by cleaving cyclin $\mathrm{E}$ at two amino-terminus domain at Ala69 and aa 40 to 45 , resulting in $44 \mathrm{kDa}$ and $33 \mathrm{kDa}$ isoforms, respectively(Porter et al., 2001). These isoforms are then phosphorylated to generate their corresponding doublets which are $45 \mathrm{kDa}$ and $34 \mathrm{kDa}$. Alternate translation at Met46 accounts for the $40 \mathrm{kDa}$ isoform, appears as a single band in western blotting (Porter et al., 2001). Compared to full length cyclin E, LMW-Es have higher affinity to CDK2 resulting in a higher CDK2 associated kinase activity, are refractory to CKIs despite binding them and are resistant to antiestrogens and aromatase inhibitors (Porter et al., 2001; Akli et al., 2004; Wingate et al., 2005; Akli et al., 2010).

Since p53 is the most frequently mutated gene in many human cancers (Knappskog and Lonning, 2012), we examined if the pathways governed by p53 and cyclin $\mathrm{E}$ are interlinked in LMW-Es mediated deregulation. In fact, there are numerous studies, which suggest a crosstalk between p53 and cyclin E pathways; including upregulation of p53 by cyclin E overexpression(Akli et al., 2004), p53 dependent harnessing of cyclin E activity through p21 and Fbxw-7 (Minella et al., 2002; Tu et al., 2013), p53 loss of heterozygosity by LMW-Es overexpression (Akli et al., 2007) and association of high cyclin E content with mutated p53(Lindahl et al., 2004). In breast cancer cells that are estrogen receptor (ER) positive, both p53 and cyclin $\mathrm{E}$ and their downstream signaling pathways governing G1 to $S$ phase transition (cyclin E and p53) and apoptosis (p53) are highly regulated. Besides, change in p53 expression or cyclin E could alter Bcl-2 and Bax expression affecting the proliferation and/or death profile. Therefore, in this study we interrogated if overexpression of LMW-Es in these ER positive breast cancer cells would lead to the deregulation of cell cycle and apoptotic pathways as a function of p53. Our results reveal that overexpression of cyclin E or LMW-Es can modulate the expression of several key proteins in both cell cycle and apoptosis pathways and this modulation when combined with p53 silencing can generate a more oncogenic phenotype.

\section{Materials and Methods}

\section{Cell culture and treatment}

MCF-7 human breast cancer cell line obtained from German Collection of Microorganisms and Cell Cultures (DSMZ, Braunschweig, Germany) Cells cultured in RPMI 1640 medium supplemented with 10\% FBS, 2mM L-glutamine, 100 units $/ \mathrm{ml}$ penicillin and $100 \mu \mathrm{g} / \mathrm{ml}$ streptomycin (all from PAA, Austria) in humidified air with $5 \% \mathrm{CO}_{2}$ at $37^{\circ} \mathrm{C}$. The cells were routinely screened for mycoplasma contamination during the experiments. For $17 \beta$-estradiol (E2) treatment, cells were switched to phenol red free RPMI 1640 medium containing $10 \%$ charcoal-treated FBS three days before experiment. Twenty-four hours before E2 stimulation, cells were seeded in 96 well cell culture plates at 10000 cell/well and at the day of treatment (at $\sim 70 \%$ of confluency), the medium was changed with medium containing 1 and 10 $\mu \mathrm{M}$ water soluble E2 (Sigma, Germany). Proliferation of individual clones following E2 treatment was measured by 3-(4,5-Dimethylthiazol-2-yl)-2, 5-diphenyltetrazolium bromide (MTT) assay at 24 and 48 hours after treatment. In each specified time $20 \mu \mathrm{l}$ of $5 \mathrm{mg} / \mathrm{ml}$ MTT (Sigma, Germany) in PBS added to each well and incubated for 4 hours at $37^{\circ} \mathrm{C}$ in foil wrapping. After adding DMSO and homogenization, the plates were read at $570 \mathrm{~nm}$ by Biotek micro plate reader. The results were corrected for background (at $690 \mathrm{~nm}$ ) and calculated as percent control.

\section{Vector construction}

The FLAG-tagged full length human Cyclin E (EL) and two of its truncated forms (T1 and T2) constructs were a kind gift from Prof. K.Keyomarsi (The University of Texas MD Anderson Cancer Center, Houston, TX). $\mathrm{T} 1$ and $\mathrm{T} 2$ encode amino acid residues 40-410 and 70-410 of full length cyclin E, respectively in pcDNA 3.1 (Invitrogen,, CA, USA) (Harwell et al., 2000). In addition to T1 and T2 we constructed Trunc mid (Tmid), which encodes amino acid residues 46-410. This vector generated using PCR by specific primers harboring restriction enzyme recognition site for directional cloning and Kozak sequence in forward primer for successful expression. The forward and reverse primers sequences are 5'-GGACACCATGGCCAAAATCGACAGG-3' and 5'-TTTCACTTGTCATGTCGTCCTTGTAGTCCG-3', respectively. The FLAG-tagged full length cyclin E was used as template. The product was then cloned into the mammalian expression vector pcDNA3.1 under the 
control of a cytomegalovirus promoter.

For creating p53 silencing construct, we used pSUPER. puro system (OligoEngine, WA, USA), which contains human H1polymerase-III promoter. The forward and reverse oligos (Eurofins MWG Operon, Germany) were designed in a way that resultant siRNA could be able to interact with all seven transcript variants of $\mathrm{p} 53$. The oligos were resuspended in water $(100 \mathrm{pmol})$ and $5 \mu \mathrm{l}$ of each were added to $40 \mu \mathrm{l}$ of annealing buffer $(20 \mathrm{mMTris} \mathrm{pH}$ 7.5, $50 \mathrm{mMNaCl}, 10 \mathrm{mM} \mathrm{MgCl} 2$ ), at $95^{\circ} \mathrm{C}$ for 10 minutes and gradually allowed to reach ambient temperature for ligation. The sequences of forward and reverse oligos were 5'-GATCCCCGACTCCAGTGGTAATCTACTTCAA GAGAGTAGATTACCACTGGAGTCTTTTTAAGCT TAT-3 ' and 5'-CGATAAGCTTAAAAAGACTCCAGTG GTAATCTACTCTCTTGAAGTAGATTACCACTGGA GTCGGG-3’, respectively.

The products of ligation reactions were then transformed into the E.coli host XL1Blue and plated on LB with antibiotic. The colonies were screened by restriction analysis and confirmed with sequencing.

\section{Stable transfection}

Transfection was carried out using PolyFect transfection reagent (Qiagen,Valencia, CA, USA). Cells were plated at $4 \times 105$ cells per each well of a 6 -well plate and transfected with the indicated vectors 24 hours following plating. Cells were transfected with $1.5 \mu$ g plasmid DNA in $100 \mu 1$ serum free medium and $12 \mu 1$ of Polyfect reagent, incubated for 10 minutes at room temperature followed by the addition of $1.5 \mathrm{ml}$ of serum containing medium and transfer of the plates to a $37^{\circ} \mathrm{C}$ humidified incubator. Transfection media was replaced by fresh media for 48 hours at which point antibiotic containing media [G418 $(500 \mu \mathrm{g} / \mathrm{ml}$, Roche, Germany) for pCDNA3.1 constructs or puromycin $(1 \mu \mathrm{g} /$ ml, Calbiochem, Germany)for pSUPER.puro] was used for selection of colonies. For each transfection thirty distinct colonies were isolated, expanded and subjected for expression screening. Selected colonies were maintained with the same concentration of G418 and puromycin as those used for selection.

\section{Western blot analysis}

Cell lysates prepared using Laemmli sample buffer $(2 \%$ SDS, $10 \%$ glycerol, $62.5 \mathrm{mM}$ Tris- $\mathrm{HCl}, \mathrm{pH} 6.8$ and $50 \mathrm{mM}$ dithiothreitol, DTT). The protein content measured by BCA Protein Assay Reagent (Thermo Sientific, US). Lysates were denatured by heating to $95^{\circ} \mathrm{C}$ for ten minutes and $50 \mu \mathrm{g}$ of each sample loaded in each lane on a $10 \%$ sodium dodecyl sulfate-polyacrylamide gel (SDS - PAGE) and subjected to gel electrophoresis. The proteins were transferred to PVDF membrane (Roche, Germany) and blots were blocked overnight at $4{ }^{\circ} \mathrm{C}$ in casein blocking buffer ( $10 \%$ casein in TBS and $0.1 \%$ tween 20$)$. Blots were then incubated at $4^{\circ} \mathrm{C}$, overnight with primary antibodies to p53, DYKDDDDK Flag, Estrogen Receptor $\alpha$, Bcl2, Bax (all from Cell signaling, MA, USA) and $\beta$-Actin (Santa Cruz, CA, USA). Following primary antibody incubation, the blots were washed and incubated with goat anti mouse/rabbit horse radish peroxidase conjugate (Biorad, Richmond, CA, USA) for 60 minutes at room temperature and developed with the BM chemiluminescence system as directed by the manufacturer (Roche, Germany). In all western blotting experiments, $\beta$-Actin was used as a loading and internal control. The quantitation of the protein bands intensity was done by ImageJ software (NIH, MD, USA).

\section{Cell cycle and proliferation assessment}

To measure DNA content, $5 \times 106$ cells were collected, rinsed by centrifuging for 5 minutes at $200 \mathrm{~g}$ with PBS. The cells were then fixed with ice cold $70 \%$ ethanol, stored at $0^{\circ} \mathrm{C}$ for at least two hours and then resuspended in $1 \mathrm{ml}$ of propidium iodide staining solution ( $2 \mathrm{mg}$ propidium iodide, $20 \mathrm{mg}$ RNase A and $100 \mu 1$ Triton X-100 in $100 \mathrm{ml}$ PBS) for 30 minutes at $37^{\circ} \mathrm{C}$. DNA content determined by CyFlow (Partec, Germany) and frequency histograms were analyzed by Flomax software (Partec, Germany) using the fluorescence values of the FL2-area channel. To measure the rate of proliferation of cells, $1 \times 104$ cells were plated in each well of a 96 well plate and at different time intervals $(4,24,48,72$ and $96 \mathrm{~h})$ cells were subjected to MTT assay.

\section{Results}

Generation of cell lines overexpressing EL/LMW-Es in presence or absence of 553

MCF-7 cells are luminal epithelial breast cancer cell line, expressing both ER and PR, low levels of LMW-Es and Her2/neu expression. Besides, this cell line is naturally devoid of LMW-Es and expressing high levels of p53. As previously described we have used the Flag tagged EL, T1, T2 and Tmid constructs to generate MCF-7 stable clones ( 2 for each construct) overexpressing each of the aforementioned isoforms. Western blot analysis of all 8 cell lines with the Flag antibody revealed that clones were overexpressing the correct protein products. Specifically, EL clones expresses the $50 \mathrm{kDa}$ full length cyclin $\mathrm{E}$, the $\mathrm{T} 1$ and $\mathrm{T} 2$ clones express the 44/45 kDa and 33/34 kDa forms, respectively, and the Tmid construct expresses the $40 \mathrm{kDa}$ form (Figure 1a).

To study the effects of p53 expression and cyclin E, we stably silenced p53 in MCF-7cells as well as in T1 and EL overexpressing clones. Western blot analysis (Figure1b) shows that the p53 is downregulated $>90 \%$ in all the clones.

Effects of cyclin E isoforms overexpression and p53 knock down on cell cycle progression

Flow cytometry revealed that overexpression of both EL and each of the LMW-Es had a profound effect on cell cycle distribution. For example the mean proportion of the cells in S phase were $28 \%, 39 \%, 40 \%$ and $32 \%$ for EL, T1,T2 and Tmid, respectively, versus $23 \%$ in controls. However the G2/M content of the cell did not change significantly except in EL overexpressing cell lines (30\% compared to $24 \%$ in control cells) (Figure 2). Silencing of p53 in parental MCF-7 was mainly associated with increased accumulation of the cells in $\mathrm{S}$ and $\mathrm{G} 2 / \mathrm{M}$ phases. However, when p53 is silenced in T1 overexpressing clones, cells accumulated in S phase while p53 silencing in EL cells resulted in the enrichment of cells in the G2/M 
phase of the cell cycle (Figure2).

Ectopic expression of cyclin E isoforms induces growth inhibition, but has synergistic effect with p53 silencing in increasing cell proliferation.

To address if changes in cell cycle distribution by overexpression of different cyclin $\mathrm{E}$ isoforms alter rate of cell proliferation, we generated growth curves for cells over a 72-hour period. The results revealed expression of EL and T1 forms of cyclin E significantly increased the doubling time of cells (28 hours for both EL and T1) as compared to vector alone cells (24 hours, Figure $3 a)$. Once, p53 was silenced, in both ELand T1 overexpressing cells a significant decrease in doubling time was observed (24 and 20 hours for EL/p53- and T1/p53- , respectively; Figure $3 \mathrm{~b}$ and $3 \mathrm{c}$ ). Overexpression of either T2 or Tmid did not significantly alter the doubling time of these cells.

ER expression was altered by both LMW-Es and p53 in MCF-7 cells

Since ER has mitogenic properties in hormone responsive cells and since both cyclin E and p53 modulate the cell cycle (see Figure2), we asked if overexpression of LMW-Es or downregulation of p53 could alter the expression of ER. To this end, we examined the expression of ER in each of the EL and LMW-Es overexpressing clones using western blotting. Results revealed that ER was induced upon EL and LMW-Es overexpression and p53 downregulation (Figure4a). Clearly, when EL or T1 overexpression was combined with p53 silencing, ER expression was also elevated; however, in EL/p53- clone, the ER protein expression was significantly lower than EL clone (Figure 4a).

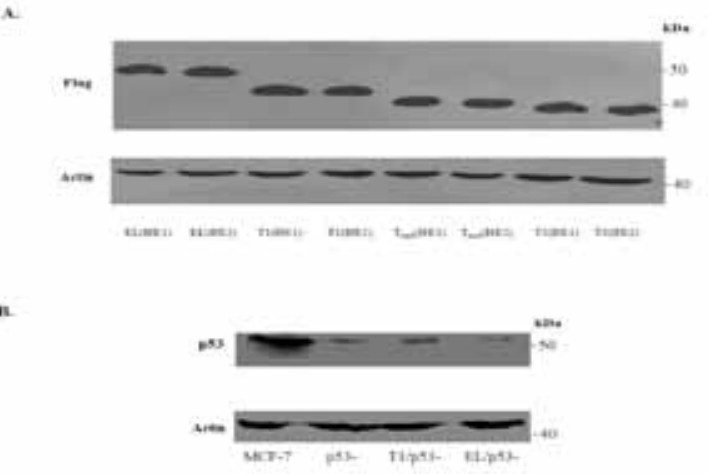

Figure 1. Western blot analyses of stable clones, A) Cyclin E Flag-tagged isoforms were overexpressed in MCF-7 cell line. MCF-7 cells were transfected by EL, T1, T2 and Tmid coding constructs. Selection procedure carried out using medium containing G-418 $(500 \mu \mathrm{g} / \mathrm{ml})$ and high expressing clones were identified by western blotting. Two different high expressing clones are defined as HE1 and HE2, B) p53 was silenced in MCF-7cells (p53-), Trunc 1 high expressing clone (T1/p53-) and full length Cyclin $E$ high expressing clone (EL/p53-). Cells transfected with p53 silencing construct using Polyfect and stable clones were selected in medium containing $1 \mu \mathrm{g} / \mathrm{ml}$ puromycin

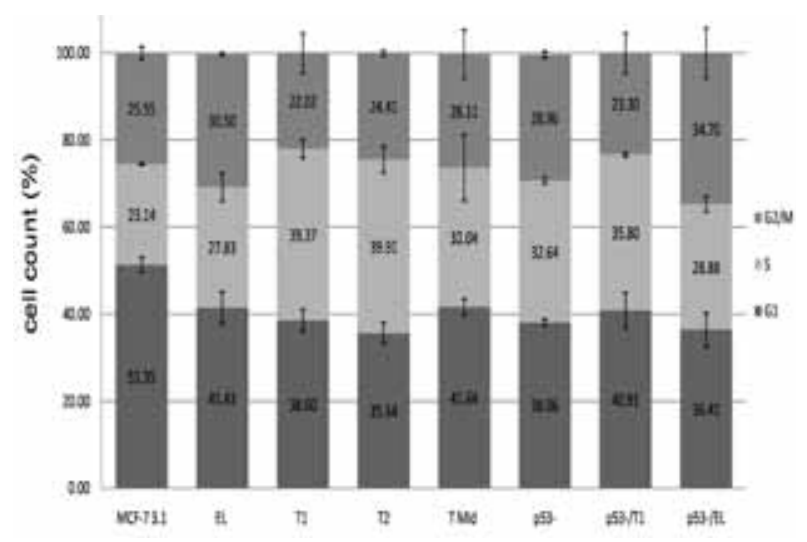

Figure 2. Cell Cycle Distribution in Cyclin E Expressing/p53 Silenced Clones. Cells were harvested at optimal density and stained with PI. The cell cycle distribution was analyzed by flow cytometry. The data are representative plots from three independent experiments (Mean \pm SEM)

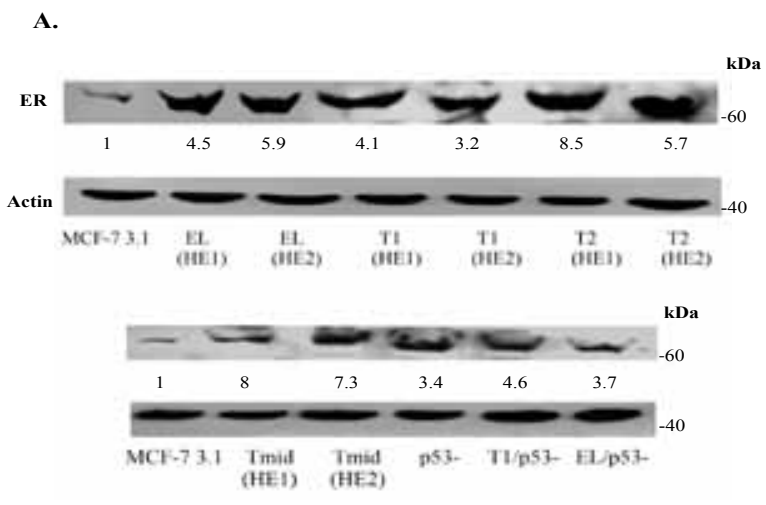

B.
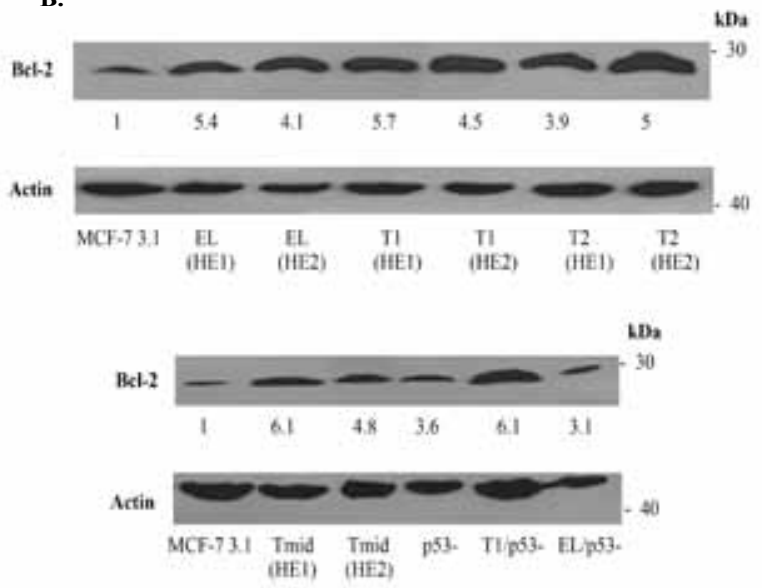

C.

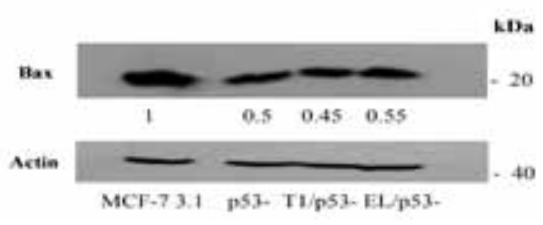

Figure 4. Western blot analysis, A) the levels of ER is elevated in response to cyclin $\mathrm{E}$ isoforms overexpression and $\mathbf{p 5 3}$ silencing, B) Bcl-2 is upregulated following cyclin $\mathrm{E}$ isoforms overexpression and p53 silencing, $\mathrm{C}$ ) Bax expression is depleted in p53-shRNA expressing cell lines. Numbers below each blot represent the mean fold induction above control 

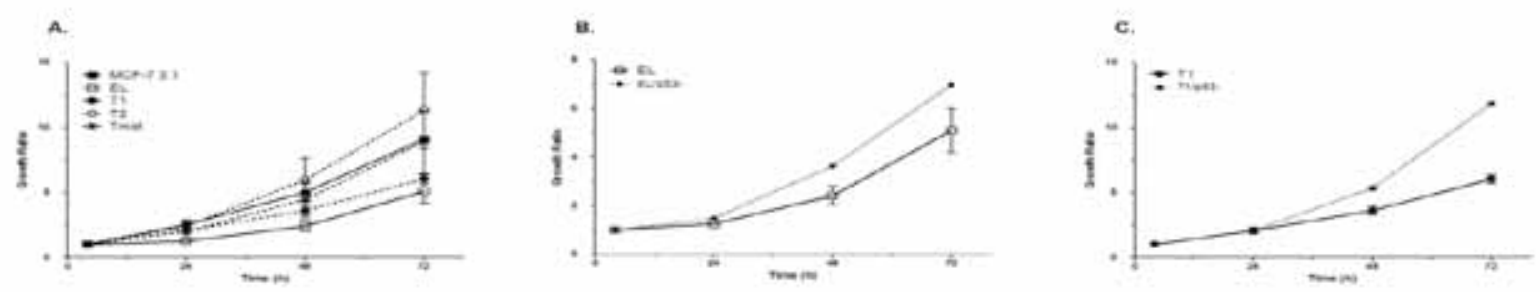

Figure 3. Different proliferation rate of stable transfectants demonstrated by MTT, A) the proliferation rate of MCF-7 3.1 cell is compared to EL, T1, T2 and Tmid clones. Expression of EL and T1 isoforms of cyclin E induces growth inhibitory effects, B) p53 silenced- EL expressing clone (EL/p53-)and (C) p53 silenced- T1 expressing clone (T1/p53-) are compared with the EL and T1 clones. Lack of p53 accelerates the growth activity in EL and $\mathrm{T} 1$ expressing clones compared to parental cells. The data are representative plots from three independent experiments (Mean \pm SEM

A.

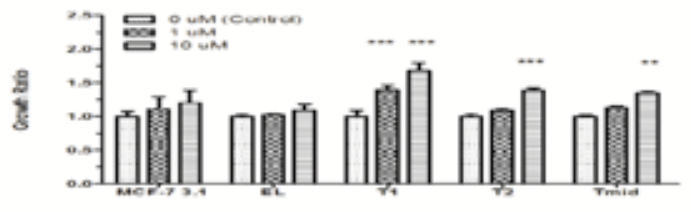

s.

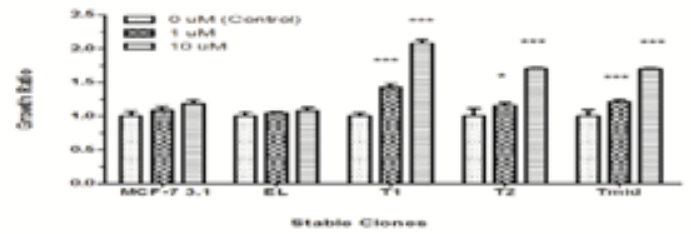

Figure 5. LMWs expressing cells respond distinctly to E2 treatment. Cells were treated with $1 \mathrm{uM}$ and $10 \mathrm{uM}$ of E2 and cell proliferation were determined by MTT assay at $24 \mathrm{~h}$ (a) and $48 \mathrm{~h}$ (b) after treatment (Mean \pm SEM, $\mathrm{n}=3$; Two way ANOVA, Bonferroni post-test $* \mathbf{P}<0.05$, **P<0.01, ***P<0.001 compared to MCF-7 3.1)

Bcl-2 and Bax expressions are affected by cyclin $E$ isoforms expression and p53 status

Since 53 is a major regulator of the apoptosis pathway, we next interrogated if downregulation of p53 could alter the expression of key apoptosis proteins ( $\mathrm{Bcl}-2$ and Bax) in the presence of EL or LMW-Es overexpression. Our results showed overexpression of EL and LMW-Es induced Bcl-2 expression. Silencing p53 in LMW-Es expressing cells had no additional changes in $\mathrm{Bcl} 2$ level (Figure 4b). On the other hand, the expression of Bax was decreased only when p53 was silenced either in parent cells or when EL and T1 were overexpressed (Figure4c).

LMW-Es but not full length cyclin E sensitize the MCF-7 cells to E2 induced proliferation

Since ER was modulated by cyclin E (see Figure4), we next asked if the E2 signaling is also altered in these cells. As shown in Figure5, E2 stimulated the growth of LMW-Es expressing cells in a time and dose dependent fashion comparing to the control cells. Specifically, overexpression of $\mathrm{T} 1$ increases the E2 (10uM) induced growth by 2 folds and T2 by $60 \%$ compared to EL clone. Proliferation of cells overexpressing EL was not modulated by E2 stimulation.

\section{Discussion}

Breast cancer, rather than a homogenous disease entity, is consisted of a variety of tumors with different molecular and clinical characteristics. Understanding the mechanisms promoting this disease holds the promise for finding more significant markers and overcoming the resistance to therapy.

Our results reveal that the expression of either EL or any of LMW-Es promotes accumulation of cells in $\mathrm{S}$ phase; however, the EL expressing clone exerts weaker effect compared to the LMW-Es expressing cells. These results refer to the function of cyclin $\mathrm{E}$ as stimulating cell cycle progression by releasing $\mathrm{E} 2 \mathrm{~F}$ from $\mathrm{Rb}$; thus induction of transcription of genes required for $\mathrm{G} 1$ to S phase transition (Hinds et al., 1992; Macdonald and Dick, 2012). However, higher proportion of S phase cells in LMW-Es expressing clones can be explained in part to their increased kinase activity and/or their resistance to inhibition by CKIs, p21 and p27 (Akli et al., 2004; Wingate et al., 2005). On the other hand, the G2 fractions in overexpressing clones are unchanged except in EL expressing cells in which proportion of G2 phase cells is increased (Figure 2). It has previously been demonstrated that overexpressing cyclin E isoforms induces p53 and p21 (Akli et al., 2004). Moreover, the cell cycle progression into the $\mathrm{M}$ phase requires $\mathrm{cdc} 2$ and PCNA which can be inhibited by p53 and p21, respectively (Cayrol et al., 1998; Ababneh et al., 2001). These consequences may increase the number of G2 cells in EL expressing clones; however, the excessive activities of LMW-Es may mask these effects.

Silencing p53 increases the population of cells in the $\mathrm{S}$ and G2 phases. This is consistent with the fact that p53 induce growth arrest through different pathways including p21, Gadd45 and 14-3-30 (Kastan et al., 1992; el-Deiry et al., 1993; Hermeking et al., 1997). However combination of p53 silencing effects (p53-) with either EL or T1 overexpression brought a different pattern of cell cycle (Figure2). EL/p53- clone displayed a mild rise in S phase and a more profound increase in G2 phase, suggesting facilitation of $\mathrm{S}$ to $\mathrm{G} 2$ in the absence of p53 in response to EL overexpression. Expression of T1 in T1/p53- clone has followed similar cell cycle profile to $\mathrm{T} 1$ clone, except a slight drop in $\mathrm{S}$ phase, which can be interpreted by the 
more prompt progression through G2 due to lack of p53.

How growth rate is affected by cyclin E overexpression and /or p53 silencing? Cells overexpressing EL or T1 showed decelerated growth rate comparing to the control cells (empty vector transfactant), which could be as a result of p53 and/or other cell cycle regulators. However, p53 deletion can eliminate these inhibitory effects and accelerates propagation rate in EL/p53- and T1/p53clones. It has been previously shown that expression of cyclin $\mathrm{E}$ isoforms decreases the doubling time of the cells in a p53 mutant human ovarian cancer cell line (MDAH-2774) and in an immortalized p53 depleted cell line (76NE6) (Band et al., 1991; Wingate et al., 2003; Bedrosian et al., 2004). Our results are in agreement with the above studies, indicating that p53 silencing can eliminate the inhibitory mechanisms raised by either EL or T1 expression. These finding are in contrast to previous results reported no significant change in doubling time of MCF-7 overexpressing EL and its LMW-Es (Akli et al., 2004). Taken together, these results demonstrated that deregulated expression of either full length or LMW forms of cyclin $\mathrm{E}$ when accompanied by lack of p53 could enhance both cell cycle progression and proliferation rate.

The status of Estrogen receptor (ER), as a nuclear transcription factor, will predict the type of systemic therapy where ER positive tumors respond better to endocrine therapy while the ER negative tumors respond better to chemotherapy (Osborne, 1998; Hess et al., 2003; Zhang et al., 2013). The relation between cyclin E and ER as a pathoclinical marker in tumor specimens has been reported where cyclin E expression is frequently seen in tumors with negative ER status (Potemski et al., 2006a; Potemski et al., 2006b). Contrary to these studies, however, we found that ER is upregulated in response to both EL and LMW-Es overexpression (Figure4a), suggesting that regulation of ER expression is downstream of cyclin $\mathrm{E}$ mediated signaling. Besides, both ER and cyclin E may be regulated in parallel by upstream factor(s), justifying the concurrent high levels of cyclin E or its LMW-Es in the absence of ER in breast cancer tissues. Considering no significant difference in ER induction between EL and LMW-Es expressing cells, LMW-Es expressing cells have enhanced sensitivity to E2, comparing to the EL or pcDNA3.1 expressing cells (Figure5). Former studies have identified a role for LMW-Es in early stages of tumor development (Shaye et al., 2009). Moreover, it has been shown that there are high ER expression (Khan et al., 1998; Smith et al., 2001; Khan et al., 2002) and lack of downregulation in ER content despite high level of serum E2 in benign breast epithelium of women with breast cancer (Khan et al., 1999; Chung et al., 2012). Besides E2 can also enhance proteolysis and expression of cyclin E (Hou et al., 2012; Niu et al., 2015). Taken our results in consideration, we demonstrate an increase in ER protein and change in E2 sensitivity because of LMW-Es expression. Thus, our findings point to the possibility that the generation of LMW-Es (which precedes normal cells transformation (Shaye et al., 2009)) can further enhance tumor development through altered ER expression and response.

Previous reports including pathoclincal and molecular ones indicate that transfection with antisense $\mathrm{p} 53$ expression vector disrupts ER expression (Angeloni et al., 2004; Panahi et al., 2013). However; our results indicate that both EL/LMW-Es overexpression and p53 ablation induces ER expression. These results suggest that either EL /LMW-Es induced p53 is not capable of ER down regulation or the cyclin $\mathrm{E}$ stimulation of $\mathrm{ER}$ expression can override the p53 effect. The discrepancy between our results and previous investigations could be explained by using different silencing technology (full length antisense RNA of p53) by other researchers (Angeloni et al., 2004).

Since the presence of apoptotic protein can determine the susceptibility of cancer cells to chemotherapy, we have studied the expression of the Bcl-2 and Bax in our stable clones.p53 is a regulator of $\mathrm{Bax}$ and $\mathrm{Bcl}-2$ gene expression. Bax expression is activated by direct binding of $\mathrm{p} 53$ to Bax gene promoter; however, Bcl-2 expression is indirectly inhibited by p53 (Haldar et al., 1994; Miyashita et al., 1994; Miyashita and Reed, 1995; Wu et al., 2001; Rengarajan et al., 2014). In our EL and LMWEs overexpressing clones, Bax expression has remained unchanged and Bcl-2 expression has been upregulated (Figure 4b). It is known that ER can directly bind p53 and suppress p53 mediated transcription including Bax (Roemer and Friedmann, 1993; Liu et al., 2006; Sayeed et al., 2007). Therefore, lack of Bax down regulation in presence of high p53 content, induced by cyclin E, can be related to elevated ER. Bcl-2 and cyclin E direct correlation, which has been shown before (Zhao et al., 2014), implies that either ER inhibits p53 expression or other regulatory pathways interfere in Bcl-2 expression and hence activate its transcription. One possible pathway which has been implied is AKT capability to regulate Bcl-2 transcription via activation of ER (Bratton et al., 2010; Jiang et al., 2012). This is further supported by positive correlation of Bcl-2 immunostaining with rising ER expression in invasive breast carcinoma (Yang et al., 1999; Jaafar et al., 2012).

In p53 negative clones, Bax is down regulated and $\mathrm{Bcl}-2$ is upregulated, although $\mathrm{Bcl}-2$ expression is higher in T1/p53- clone. Bcl-2 upregulation can inhibit apoptosis by two different mechanisms. Bcl-2 can form homodimers and also sequesters $\mathrm{BH}-3$ only proteins, thus hampering the activation of Bax and Bak proteins (Oltvai et al., 1993; Yin et al., 1994; Raghav et al., 2012). Bax downregulation also reduces cell vulnerability to apoptosis by reducing formation of Bax homodimers and/or Bcl-2/ Bax heterodimers, resulting in cell death. Collectively, these observations suggest that overexpression of cyclin E isoforms, especially in the absence of p53; can augment Bcl-2/Bax ratio and thus resistance to cytotoxic drugs.

In summary, our findings suggest that the role of cyclin E and LMW-Es as mediators of tumorigenesis is in part dependent on p53 context. Although aberrant expression of cyclin $\mathrm{E}$ confers aggressive phenotypes on cancer cells, due to the interplay between p53 and cyclin E signaling events, concomitant overexpression of cyclin $\mathrm{E}$ with the loss of p53 can further enhance tumor growth and resistance to apoptosis. Moreover, LMW-Es alter ER responsivity and expression thus predispose non-malignant cell either in high risk persons 
or carcinomatous adjacent tissue to invasive carcinoma. These data will help for better understanding of how cyclin E overexpression contributes to tumorigenesis; hence, provide more successful molecularly based strategies for cancer therapies.

\section{Acknowledgements}

This project is financially supported by research grants from Pasteur Institute of Iran. We are indebted to Prof. K.Keyomarsi for critical reading the manuscript and freely providing EL, T1 and T2 plasmids. The authors would like to thank Mr. H. Akbari and A. R. Kazemi for technical assistance.

\section{References}

Ababneh M, Gotz C, Montenarh M (2001). Downregulation of the $\mathrm{cdc} 2 /$ cyclin $\mathrm{B}$ protein kinase activity by binding of $\mathrm{p} 53$ to p34(cdc2). Biochem Biophys Res Commun, 283, 507-12.

Akli S, Bui T, Wingate H, et al (2010). Low-molecular-weight cyclin E can bypass letrozole-induced G1 arrest in human breast cancer cells and tumors. Clin Cancer Res, 16, 1179-90.

Akli S, Van Pelt CS, Bui T, et al (2007). Overexpression of the low molecular weight cyclin $\mathrm{E}$ in transgenic mice induces metastatic mammary carcinomas through the disruption of the ARF-p53 pathway. Cancer Res, 67, 7212-22.

Akli S, Zheng PJ, Multani AS, et al (2004). Tumor-specific low molecular weight forms of cyclin $\mathrm{E}$ induce genomic instability and resistance to $\mathrm{p} 21, \mathrm{p} 27$, and antiestrogens in breast cancer. Cancer Res, 64, 3198-208.

Alsina M,Landolfi S, Aura C, et al (2015). Cyclin E amplification/ overexpression is associated with poor prognosis in gastric cancer. Ann Oncol, 26, 438-9.

Angeloni SV, Martin MB, Garcia-Morales P, et al (2004). Regulation of estrogen receptor-alpha expression by the tumor suppressor gene p53 in MCF-7 cells. $J$ Endocrinol, 180, 497-504.

Band V, De Caprio JA, Delmolino L, et al (1991). Loss of p53 protein in human papillomavirus type 16 E6-immortalized human mammary epithelial cells. J Virol, 65, 6671-6.

Bedrosian I, Lu KH, Verschraegen C, et al (2004). Cyclin E deregulation alters the biologic properties of ovarian cancer cells. Oncogene, 23, 2648-57.

Bratton MR, Duong BN, Elliott S, et al (2010). Regulation of ERalpha-mediated transcription of $\mathrm{Bcl}-2$ by PI3K-AKT crosstalk: implications for breast cancer cell survival. Int $J$ Oncol, 37, 541-50.

Caldon CE, Sergio CM, Kang J, et al (2012). Cyclin E2 overexpression is associated with endocrine resistance but not insensitivity to CDK2 inhibition in human breast cancer cells. Mol Cancer Ther, 11, 1488-99.

Cayrol C, Knibiehler M, Ducommun B (1998). p21 binding to PCNA causes G1 and G2 cell cycle arrest in p53-deficient cells. Oncogene, 16, 311-20.

Chung K, Hovanessian-Larsen LJ, Hawes D, et al (2012). Breast epithelial cell proliferation is markedly increased with short-term high levels of endogenous estrogen secondary to controlled ovarian hyperstimulation. Breast Cancer Res Treat, 132, 653-60.

Davidson B, Skrede M, Silins I, et al (2007). Low-molecular weight forms of cyclin $\mathrm{E}$ differentiate ovarian carcinoma from cells of mesothelial origin and are associated with poor survival in ovarian carcinoma. Cancer, 110, 1264-71. Donnellan R, Chetty R (1999). Cyclin E in human cancers.
FASEB J, 13, 773-80.

Dulic V, Drullinger LF, Lees E, et al (1993). Altered regulation of $\mathrm{G} 1$ cyclins in senescent human diploid fibroblasts: accumulation of inactive cyclin E-Cdk2 and cyclin D1-Cdk2 complexes. Proc Natl Acad Sci USA, 90, 11034-8.

Ekholm-Reed S, Spruck CH, Sangfelt O, et al (2004). Mutation of hCDC4 leads to cell cycle deregulation of cyclin E in cancer. Cancer Res, 64, 795-800.

Ekholm SV, Reed SI (2000). Regulation of G(1) cyclindependent kinases in the mammalian cell cycle. Curr Opin Cell Biol, 12, 676-84.

el-Deiry WS, Tokino T, Velculescu VE, et al (1993). WAF1, a potential mediator of p53 tumor suppression. Cell, $\mathbf{7 5}$, 817-25.

Gao S, Ma JJ, Lu C (2013). Prognostic value of cyclin E expression in breast cancer: a meta-analysis. Tumour Biol, 34, 3423-30.

Gladden AB, Diehl JA (2003). Cell cycle progression without cyclin E/CDK2: breaking down the walls of dogma. Cancer Cell, 4, 160-2.

Haldar S, Negrini M, Monne M, et al (1994). Down-regulation of bcl-2 by p53 in breast cancer cells. Cancer Res, 54, 2095-7.

Harwell RM, Porter DC, Danes C, et al (2000). Processing of cyclin E differs between normal and tumor breast cells. Cancer Res, 60, 481-9.

Hermeking H, Lengauer C, Polyak K, et al (1997). 14-3-3 sigma is a p53-regulated inhibitor of $\mathrm{G} 2 / \mathrm{M}$ progression. Mol Cell, 1, 3-11.

Hess KR, Pusztai L, Buzdar AU, et al (2003). Estrogen receptors and distinct patterns of breast cancer relapse. Breast Cancer Res Treat, 78, 105-18.

Hinds PW, Mittnacht S, Dulic V, et al (1992). Regulation of retinoblastoma protein functions by ectopic expression of human cyclins. Cell, 70, 993-1006.

Hou J, Wang X, Li Y, et al (2012). 17beta-estradiol induces both up-regulation and processing of cyclin $\mathrm{E}$ in a calpaindependent manner in MCF-7 breast cancer cells. FEBS Lett, 586, 892-6.

Hwang HC, Clurman BE (2005). Cyclin E in normal and neoplastic cell cycles. Oncogene, 24, 2776-86.

Jaafar H, Abdullah S, Murtey MD, et al (2012). Expression of Bax and Bcl-2 in tumour cells and blood vessels of breast cancer and their association with angiogenesis and hormonal receptors. Asian Pac J Cancer Prev, 13, 3857-62.

Jiang Z, Guo J, Shen J, et al (2012). The role of estrogen receptor alpha in mediating chemoresistance in breast cancer cells. $J$ Exp Clin Cancer Res, 31, 42.

Kastan MB, Zhan Q, el-Deiry WS, et al (1992). A mammalian cell cycle checkpoint pathway utilizing p53 and GADD45 is defective in ataxia-telangiectasia. Cell, 71, 587-97.

Keyomarsi K, Conte D, Jr, Toyofuku W, et al (1995). Deregulation of cyclin E in breast cancer. Oncogene, 11, 941-50.

Keyomarsi K, Pardee AB (1993). Redundant cyclin overexpression and gene amplification in breast cancer cells. Proc Natl Acad Sci U S A, 90, 1112-6.

Keyomarsi K, Tucker SL, Buchholz TA, et al (2002). Cyclin E and survival in patients with breast cancer. $N$ Engl J Med, 347, 1566-75.

Khan SA, Rogers MA, Khurana KK, et al (1998). Estrogen receptor expression in benign breast epithelium and breast cancer risk. J Natl Cancer Inst, 90, 37-42.

Khan SA, Sachdeva A, Naim S, et al (1999). The normal breast epithelium of women with breast cancer displays an aberrant response to estradiol. Cancer Epidemiol Biomarkers Prev, 8, 867-72.

Khan SA, Yee KA, Kaplan C, et al (2002). Estrogen receptor alpha expression in normal human breast epithelium is 
consistent over time. Int J Cancer, 102, 334-7.

Knappskog S, Lonning PE (2012). P53 and its molecular basis to chemoresistance in breast cancer. Expert Opin Ther Targets, 16, 23-30.

Koff A, Cross F, Fisher A, et al (1991). Human cyclin E, a new cyclin that interacts with two members of the $\mathrm{CDC} 2$ gene family. Cell, 66, 1217-28.

Lauper N, Beck AR, Cariou S, et al (1998). Cyclin E2: a novel CDK2 partner in the late $\mathrm{G} 1$ and $\mathrm{S}$ phases of the mammalian cell cycle. Oncogene, 17, 2637-43.

le Sage C, Nagel R, Egan DA, et al (2007). Regulation of the p27(Kip1) tumor suppressor by miR-221 and miR-222 promotes cancer cell proliferation. EMBO J, 26, 3699-708.

Lindahl T, Landberg G, Ahlgren J, et al (2004). Overexpression of cyclin E protein is associated with specific mutation types in the p53 gene and poor survival in human breast cancer. Carcinogenesis, 25, 375-80.

Liu SZ, Zhang F, Chang YX, et al (2013). Prognostic impact of cyclin D1, cyclin E and P53 on gastroenteropancreatic neuroendocrine tumours. Asian Pac J Cancer Prev, 14, 419-22.

Liu W, Konduri SD, Bansal S, et al (2006). Estrogen receptoralpha binds p53 tumor suppressor protein directly and represses its function. $J$ Biol Chem, 281, 9837-40.

Liu X, Sempere LF, Galimberti F, et al (2009). Uncovering growth-suppressive MicroRNAs in lung cancer. Clin Cancer Res, 15, 1177-83.

Macdonald JI, Dick FA (2012). Posttranslational modifications of the retinoblastoma tumor suppressor protein as determinants of function. Genes Cancer, 3, 619-33.

Minella AC, Swanger J, Bryant E, et al (2002). p53 and p21 form an inducible barrier that protects cells against cyclin E-cdk2 deregulation. Curr Biol, 12, 1817-27.

Miyashita T, Krajewski S, Krajewska M, et al (1994). Tumor suppressor p53 is a regulator of bcl-2 and bax gene expression in vitro and in vivo. Oncogene, 9, 1799-805.

Miyashita T, Reed JC (1995). Tumor suppressor p53 is a direct transcriptional activator of the human bax gene. Cell, $\mathbf{8 0}$, 293-9.

Niu D, Wang G, Wang X (2015). Up-regulation of cyclin E in breast cancer via estrogen receptor pathway. Int J Clin Exp Med, 8, 910-5.

Ohtani K, DeGregori J, Nevins JR (1995). Regulation of the cyclin E gene by transcription factor E2F1. Proc Natl Acad Sci U S A, 92, 12146-50.

Ohtsubo M, Theodoras AM, Schumacher J, et al (1995). Human cyclin E, a nuclear protein essential for the G1-to-S phase transition. Mol Cell Biol, 15, 2612-24.

Oltvai ZN, Milliman CL, Korsmeyer SJ (1993). Bcl-2 heterodimerizes in vivo with a conserved homolog, Bax, that accelerates programmed cell death. Cell, 74, 609-19.

Osborne CK (1998). Steroid hormone receptors in breast cancer management. Breast Cancer Res Treat, 51, 227-38.

Panahi M, Saki N, Ashourzadeh S, et al (2013). Expressional correlation of human epidermal growth factor receptor 2 , estrogen/progesterone receptor and protein 53 in breast cancer. Asian Pac J Cancer Prev, 14, 3699-703.

Porter DC, Zhang N, Danes C, et al (2001). Tumor-specific proteolytic processing of cyclin $\mathrm{E}$ generates hyperactive lower-molecular-weight forms. Mol Cell Biol, 21, 6254-69.

Potemski P, Kusinska R, Watala C, et al (2006a). Cyclin $\mathrm{E}$ expression in breast cancer correlates with negative steroid receptor status, HER2 expression, tumor grade and proliferation. J Exp Clin Cancer Res, 25, 59-64.

Potemski P, Pluciennik E, Bednarek AK, et al (2006b). Cyclin E expression in operable breast cancer quantified using realtime RT-PCR: a comparative study with immunostaining.
Jpn J Clin Oncol, 36, 142-9.

Raghav PK, Verma YK, Gangenahalli GU (2012). Peptide screening to knockdown Bcl-2's anti-apoptotic activity: implications in cancer treatment. Int J Biol Macromol, 50, 796-814.

Rengarajan T, Nandakumar N, Rajendran P, et al (2014). D-pinitol promotes apoptosis in MCF-7 cells via induction of $\mathrm{p} 53$ and Bax and inhibition of Bcl-2 and NF-kappaB. Asian Pac J Cancer Prev, 15, 1757-62.

Richardson H, O'Keefe LV, Marty T, et al (1995). Ectopic cyclin $\mathrm{E}$ expression induces premature entry into $\mathrm{S}$ phase and disrupts pattern formation in the Drosophila eye imaginal disc. Development, 121, 3371-9.

Roemer K, Friedmann T (1993). Modulation of cell proliferation and gene expression by a p53-estrogen receptor hybrid protein. Proc Natl Acad Sci U S A, 90, 9252-6.

Sayeed A, Konduri SD, Liu W, et al (2007). Estrogen receptor alpha inhibits p53-mediated transcriptional repression: implications for the regulation of apoptosis. Cancer Res, 67, 7746-55.

Scuderi R, Palucka KA, Pokrovskaja K, et al (1996). Cyclin $\mathrm{E}$ overexpression in relapsed adult acute lymphoblastic leukemias of B-cell lineage. Blood, 87, 3360-7.

Shaye A, Sahin A, Hao Q, et al (2009). Cyclin E deregulation is an early event in the development of breast cancer. Breast Cancer Res Treat, 115, 651-9.

Smith FB, Puerto CD, Sagerman P (2001). Relationship of estrogen and progesterone receptor protein levels in carcinomatous and adjacent non-neoplastic epithelium of the breast: a histopathologic and image cytometric study. Breast Cancer Res Treat, 65, 241-7.

Spruck CH, Won KA, Reed SI (1999). Deregulated cyclin E induces chromosome instability. Nature, 401, 297-300.

Tu K, Zheng X, Zhou Z, et al (2013). Recombinant human adenovirus-p53 injection induced apoptosis in hepatocellular carcinoma cell lines mediated by $\mathrm{p} 53-\mathrm{Fbxw} 7$ pathway, which controls c-Myc and cyclin E. PLoS One, 8, 68574.

Wang A, Yoshimi N, Suzui M, et al (1996). Different expression patterns of cyclins A, D1 and E in human colorectal cancer. J Cancer Res Clin Oncol, 122, 122-6.

Weinberg RA (1995). The retinoblastoma protein and cell cycle control. Cell, 81, 323-30.

Wingate H, Bedrosian I, Akli S, et al (2003). The low molecular weight (LMW) isoforms of cyclin E deregulate the cell cycle of mammary epithelial cells. Cell Cycle, 2, 461-6.

Wingate H, Zhang N, McGarhen MJ, et al (2005). The tumorspecific hyperactive forms of cyclin $\mathrm{E}$ are resistant to inhibition by $\mathrm{p} 21$ and p27. J Biol Chem, 280, 15148-57.

Wu Y, Mehew JW, Heckman CA, et al (2001). Negative regulation of bcl- 2 expression by $\mathrm{p} 53$ in hematopoietic cells. Oncogene, 20, 240-51.

Xiong Y, Connolly T, Futcher B, et al (1991). Human D-type cyclin. Cell, 65, 691-9.

Yang Q, Sakurai T, Jing X, et al (1999). Expression of Bcl-2, but not Bax, correlates with estrogen receptor status and tumor proliferation in invasive breast carcinoma. Pathol Int , 49, 775-80.

Yin XM, Oltvai ZN, Korsmeyer SJ (1994). BH1 and BH2 domains of Bcl-2 are required for inhibition of apoptosis and heterodimerization with Bax. Nature, 369, 321-3.

Zhang XH, Giuliano M, Trivedi MV, et al (2013). Metastasis dormancy in estrogen receptor-positive breast cancer. Clin Cancer Res, 19, 6389-97.

Zhao LW, Zhong XH, Yang SY, et al (2014). Inotodiol inhabits proliferation and induces apoptosis through modulating expression of cyclinE, p27, bcl-2, and bax in human cervical cancer HeLa cells. Asian Pac J Cancer Prev, 15, 3195-9. 